\title{
LIMITAÇÓES AO EXERCÍCIO DA COMPETÊNCIA TRIBUTÁRIA RESIDUAL EM FACE DO PRINCÍPIO DE CORREÇÃO FUNCIONAL
}

\author{
LIMITS ON THE EXERCISE OF RESIDUAL \\ TAXING POWER ACCORDING TO THE PRINCIPLE \\ OF FUNCTIONAL CORRECTNESS
}

THIAGO ÁlVARES FEITAL ${ }^{1}$

\section{RESUMO}

O presente trabalho tem por objetivo verificar se existem na Constituição da República outras limitações ao exercício da competência tributária residual, além daquelas enunciadas nos artigos 154, I e 195, § $4^{\circ}$. Para tanto, a partir de uma interpretação crítica da competência tributária residual, por meio de método dedutivo, e adotando como referencial teórico o princípio da correção funcional sistematizado por Friedrich Müller, demonstramos que este exige que se considerem os efeitos do federalismo sobre o Sistema Tributário. Após revisar os conceitos de federalismo e federalismo fiscal na literatura recente e a analisar a sua adequação à Constituição fiscal brasileira, concluímos que a competência tributária residual é limitada pelo princípio de correção funcional. Os resultados da pesquisa indicam que o exercício da competência residual não pode ofender a equalização fiscal, porque esta é componente da forma federativa do Estado brasileiro.

PALAVRAS-CHAVE: Competência residual. Competência tributária. Contribuições sociais residuais. Federalismo fiscal.

\section{ABSTRACT}

The purpose of this paper is to verify whether the Brazilian Constitution contains any other limitations on the exercise of residual taxing power, other than those set forth in articles 154, I and 195, paragraph 4. For this purpose, based on a critical interpretation of the residual taxing power, using a deductive method, and adopting as a theoretical reference the principle of functional correctness, as systematized by Friedrich Müller, we demonstrate that this requires considering the effects of federalism on the Tax System. After reviewing the concepts of federalism and fiscal federalism in the recent literature and analyzing their adequacy to the Brazilian fiscal constitution, we conclude that the residual taxing power is limited by the principle of functional correctness. The results of the research indicate that the exercise of residual taxing power cannot offend the tax equalization, because the latter is a component of the federative form of the Brazilian State.

KEYWORDS: Fiscal Federalism. Residual Social Contributions. Residual Taxing Power. Taxing Power.

1 Professor das Faculdades Milton Campos. Foi professor da disciplina Direito Tributário no curso de graduação em Ciências Contábeis da UFMG (2017). Mestre em Direito pela UFMG (2017). Especialista em Direito Tributário pela Pontifícia Universidade Católica de Minas Gerais (2016). Doutorando em Direito pela UFMG (2018).E-mail: thiago.feitalv@gmail.com 


\section{INTRODUÇÃO}

O ano de 2018 em que se celebraram os trinta anos de promulgação da Constituição da República (CR) é também um ponto crítico para o federalismo no Brasil, como o demonstra o ajuizamento da Arguição de Descumprimento de Preceito Fundamental n 523, em 11 de junho de 2018. Subscrita por vinte e três Estados, além do Distrito Federal, a ação questiona a alteração do perfil financeiro das contribuições residuais operada por meio da perpetuação do mecanismo de Desvinculação das Receitas da União (DRU), criado pela Emenda Constitucional $n^{\circ} 27$, de $2000^{2}$. Para os peticionantes, ao prorrogar a vigência da DRU repetidas vezes $^{3}$ a União vem praticando fraude à Constituição, burlando o esquema constitucional de repartição de receitas tributárias - especialmente o artigo 157, II, CR - e violando o próprio princípio federativo.

A ação convida a uma reflexão teórica sobre a relação entre o federalismo e o Sistema Tributário Nacional (STN) na Constituição de 1988, matéria de interesse primordial para o Direito Tributário ${ }^{4}$, o que justifica acadêmica e socialmente este trabalho. Como se sabe, a técnica de repartição de competências tributárias adotada pela Constituição é uma das projeções do federalismo no campo da tributação, justamente aquela que, concedendo autonomia financeira aos entes federados, torna efetiva a sua autonomia política e jurídica ${ }^{5}$.

Com o objetivo de enriquecer a literatura relativa ao tema e fomentar a reflexão sobre o equilíbrio federativo na Constituição trigenária, no presente artigo pretende-se responder o seguinte problema de pesquisa: é possível identificar na CR limitações ao exercício da competência tributária residual, para além das condicionantes enunciadas nos arts. 154, I e 195, $\S 4^{\circ}, \mathrm{CR}$ ?

Partindo do princípio de conformidade funcional - adotado como referencial teórico na forma que o conceito recebeu na sistematização feita por Friedrich Müller - verificaremos se o exercício da competência tributária residual pela União deve sujeitar-se a este princípio.

Para tanto, o presente trabalho encontra-se dividido em quatro seções, além desta introdução e de sua conclusão. Na primeira seção serão articulados os marcos conceituais

2 BRASIL. Emenda Constitucional n 27, de 2000. Acrescenta o art. 76 ao Ato das Disposições Constitucionais Transitórias, instituindo a desvinculação de arrecadação de impostos e contribuições sociais da União. Disponível em: http://www2. camara.leg.br/legin/fed/emecon/2000/emendaconstitucional-27-21-marco-2000-373981-publicacaooriginal-1-pl.html. Acesso em: 08 ago. 2018.

3 Cf. BRASIL. Emenda Constitucional n 42, de 2003. Altera o Sistema Tributário Nacional e dá outras providências. Disponível em: http://www2.camara.leg.br/legin/fed/emecon/2003/emendaconstitucional-42-19-dezembro-2003-497205-norma-pl.html. Acesso em: 08 ago. 2018.

BRASIL. Emenda Constitucional n 56, de 2007. Prorroga o prazo previsto no caput do art. 76 do Ato das Disposições Constitucionais Transitórias e dá outras providências. Disponível em: http://www2.camara.leg.br/legin/fed/emecon/2007/ emendaconstitucional-56-20-dezembro-2007-567249-norma-pl.html. Acesso em: 08 ago. 2017.

BRASIL. Emenda Constitucional n 68, de 2011. Altera o art. 76 do Ato das Disposições Constitucionais Transitórias. Disponível em: http://www2.camara.leg.br/legin/fed/emecon/2011/emendaconstitucional-68-21-dezembro-2011-612061-publicacaooriginal-134728-pl.html. Acesso em: 08 ago. 2018.

BRASIL. Emenda Constitucional Nº 93, de 2016. Altera o Ato das Disposições Constitucionais Transitórias para prorrogar a desvinculação de receitas da União e estabelecer a desvinculação de receitas dos Estados, Distrito Federal e Municípios. Disponível em: http://www2.camara.leg.br/legin/fed/emecon/2016/emendaconstitucional-93-8-setembro-2016-783591-publicacaooriginal-151044-pl.html. Acesso em: 08 ago. 2018.

40 campo de estudos do Direito Tributário, que não se confunde cientificamente com aquele do Direito Financeiro, é composto também pela investigação das normas que "[...] delimitam e coordenam as potestades tributárias entre as distintas esferas de poder nos países com regime federal de governo". VILLEGAS, Hector B. Curso de finanzas, derecho financiero y tributario. Buenos Aires: Ediciones Depalma, 2001. p. 185. Tradução livre.

5 COÊLHO, Sacha Calmon Navarro. Curso de direto tributário brasileiro. Rio de Janeiro: Forense, 2018. p. 43-45. No mesmo sentido: DA SILVA, José Afonso. Curso de direito constitucional positivo. São Paulo: Malheiros, 2011. p. 478. 
necessários para se situar o problema do federalismo fiscal brasileiro. Tendo em vista a vastidão da literatura acerca do tema, serão expostos apenas os conceitos mais fundamentais, sem qualquer pretensão de se elaborar uma revisão exaustiva. A seguir, apresenta-se a estrutura de repartição de competências e de receitas tributárias contida na Constituição de 1988. A compreensão deste arcabouço financeiro, cerne da Constituição fiscal brasileira, é fundamental para que se possa enfrentar adequadamente o problema de pesquisa proposto. Na quarta seção vai-se discorrer acerca do princípio hermenêutico de conformidade funcional, no intuito de se identificar seu conteúdo normativo. Considerando-se a literatura existente, será proposta uma definição que se acredita mais condizente com a dignidade que o princípio do federalismo assume na Constituição em vigor. Finalmente, o princípio desvelado na seção anterior será utilizado como marco normativo para se identificar as limitações sistêmicas que condicionam o exercício da competência residual.

\section{FEDERALISMO E FEDERALISMO FISCAL: ELEMENTOS CONCEITUAIS}

Antes de se passar ao enfrentamento da questão posta neste trabalho, mostra-se necessário estabelecer o que se entende por federalismo e federalismo fiscal, noções que constituem o fundamento teórico da presente investigação.

A multiplicidade de formas adotadas por Estados federais ao redor do mundo torna hercúlea a tarefa de desenvolver uma teoria minimamente abrangente do fenômeno ${ }^{6}$. É por esta razão que o objetivo de elaborar uma teoria capaz de fornecer prescrições que se aplicariam indistintamente a todos os sistemas deve ser abandonado? ${ }^{7}$. Esta, que é a abordagem clássica, deve ser substituída por uma definição tipológica do federalismo, capaz de reconhecê-lo e analisá-lo em suas múltiplas formas, quer como princípio de organização política ${ }^{8}$, na acepção jurídica, quer como ethos político ${ }^{9}$, na acepção filosófica.

Conquanto seja expressiva a evolução semântica do federalismo na história, a estrutura fundamental do tipo federal é singela. Segundo a teoria clássica, tem-se no modelo federal a divisão do poder entre um centro e sua periferia. Em princípio, um Estado se diz federal quando se sujeita àquilo que pode ser denominado de dualidade de governança ${ }^{10}$. Esta dualidade verifica-se quando, após a reunião das partes que integram o pacto federativo,

6 VILE, M.J.C. Federal Theory and the "New Federalism". In: JAENSCH, D. (ed.) The Politics of New Federalism. Adelaide: Australian Political Studies Association, 1977. p. 01.

7 BURGESS, Michael. Comparative Federalism: Theory and Practice. London: Routledge, 2006. p. 45.

8 DERZI, Misabel de Abreu Machado; DE BUSTAMANTE, Thomas da Rosa. 0 princípio federativo e a igualdade: uma perspectiva crítica para o sistema jurídico brasileiro a partir da análise do modelo alemão. In: DERZI, Misabel de Abreu Machado; BATISTA JÚNIOR, Onofre Alves; MOREIRA, André Mendes. Estado federal e guerra fiscal no direito comparado. Belo Horizonte: Arraes, 2015. p. 470.

9 MOOTS, Glenn A. The Covenant Tradition of Federalism: The Pioneering Studies of Daniel J. Elazar. In: WARD, Ann; WARD, Lee. (eds.). The Ashgate Research Companion to Federalism. Farnham: Ashgate, 2009. p. 399.

10 SACCHETTO, C. Analysis of Fiscal Federalism from a Comparative Tax Law Perspective. In: BIZIOLI, G.; SACCHETTO, C. (eds.). Tax Aspects of Fiscal Federalism: A Comparative Analysis. Amsterdam: IBFD, 2011. p. 12. 
configuram-se dois níveis politicamente autônomos, o que implicará na existência de duas ordens jurídicas distintas ${ }^{11}$, fenômeno recorrentemente denominado de descentralização ${ }^{12}$.

Apesar de bastante difundida, a visão dualista é insuficiente. Para se compreender as estruturas federais encontradiças na atualidade, é mais adequado recorrer à teoria proposta por Daniel Elazar. Segundo o autor, o federalismo é uma forma de distribuição do poder sem um centro focal, em um arranjo de interdependência, no qual os diferentes componentes coordenam-se em torno de múltiplos centros ${ }^{13}$. Neste esquema, a força política não se contra no centro ou na periferia, mas na tensão da rede como um todo ${ }^{14}$.

Esquematicamente, as formas de distribuição de poder entre as entidades subnacionais e a União podem assumir a forma do federalismo dual ${ }^{15}$; cooperativo $^{16}$; ou competitivo ${ }^{17}$. As duas primeiras correspondem a modelos históricos, isto é, empiricamente verificáveis nos sistemas políticos existentes no passado ou no presente. No federalismo dual - encontrado, por exemplo, no México, Malásia, Rússia, Canadá, Austrália, Estados Unidos, Índia e Paquistão - os entes nacional e subnacionais exercem suas competências de forma independente. Cada ente é soberano em relação às competências que the foram outorgadas e nenhum deles é soberano em relação às competências outorgadas aos demais ${ }^{18}$. A relação que deriva deste esquema inclina-se muito mais à tensão, do que à colaboração ${ }^{19}$. É o que opõe o federalismo dual ao federalismo de cooperação. Neste último - atualmente praticado, por exemplo, na Alemanha, África do Sul e Bélgica, além do Brasil - há um harmônico equilíbrio entre a atuação dos diversos entes, que se caracteriza pela partilha de responsabilidades sobre uma mesma área de atuação ${ }^{20}$. Finalmente, o federalismo competitivo - modelo acadêmico que não encontra aplicação em nenhum sistema político atual - propõe que os entes federados possuam atribuições idênticas, de modo a maximizar a competição entre eles, o que supostamente resultaria em um ganho de eficiência na prestação dos serviços públicos ${ }^{21}$.

11 "A organização do Estado Federal é tarefa de laboriosa engenharia constitucional. É que o Estado Federal requer duplo ordenamento, desencadeando as normas e as regras próprias a cada um. Refiro-me ao ordenamento da Federação ou da União e aos ordenamentos jurídicos dos Estados-membros."

HORTA, Raul Machado. Organização Constitucional do Federalismo. Revista da Faculdade de Direito da UFMG, n. 28-29, p. 09-32, 1986. p. 10.

12 Importa ressaltar que a descentralização fiscal não é característica exclusiva das federações, mas pode ser encontrada também em Estados unitários, que fazem uso de delegações de poderes para autoridades locais (devolutions), no intuito de tornar praticável a administração da coisa pública. Cf. BOADWAY, Robin; SHAH, Anwar. Fiscal Federalism: Principles and Practices of Multiorder Governance. Cambridge: Cambridge University Press, 2009. p. 61.

Além disso, a descentralização administrativa permite aproximar as esferas de poder das necessidades dos cidadãos. Cf. SHAH, Anwar. Introduction: Principles of Fiscal Federalism. In: SHAH, Anwar. The Practice of Fiscal Federalism: Comparative Perspectives. Montréal: McGill-Queen's University Press, 2007. p. 10.

13 ELAZAR, Daniel J. Federalism and Political Integration. Lanham: University Press of America, 1984. p. 15.

14 MOOTS, Glenn A. The Covenant Tradition of Federalism: The Pioneering Studies of Daniel J. Elazar. In: WARD, Ann; WARD, Lee. (eds.). The Ashgate Research Companion to Federalism. Farnham: Ashgate, 2009. p. 400.

15 Para a tipologia dupla do federalismo dual (layer cake e coordinate-authority), veja-se: SHAH, Anwar. Introduction: Principles of Fiscal Federalism. In: SHAH, Anwar. The Practice of Fiscal Federalism: Comparative Perspectives. Montréal: McGill-Queen's University Press, 2007. p. 05.

16 Para a tipologia dupla do federalismo cooperativo (interdependente spheres, marble cake e independente spheres) veja-se: SHAH, Anwar. Introduction: Principles of Fiscal Federalism. In: The Practice of Fiscal Federalism: Comparative Perspectives. Montréal: McGill-Queen's University Press, 2007. p. 05.

17 Para um aprofundamento: BRENNAN, G.; BUCHANAN, J. The Power to Tax: Analytical Foundations of a Fiscal Constitution. Cambridge: Cambridge University Press, 1980.

18 SCHÜTZE, Robert. From Dual to Cooperative Federalism: The Changing Structure of European Law. Oxford: Oxford University Press, 2009. p. 78.

19 CORWIN, Edward S. The passing of dual federalism. Virginia Law Review, v. 36, n. 01, p. 01-24, 1950.

20 BARACHO, José Alfredo de Oliveira. Teoria geral do federalismo. Rio de Janeiro: Forense, 1986.

21 "[...] if the citizens of a jurisdiction appraise the performance of their government by comparing it to the performance of governments elsewhere but at the same jurisdictional level, they would induce their own government to do as well as or 
Dentro deste complexo cenário, a criação da estrutura normativa mais adequada para repartir a responsabilidade pelas despesas e as fontes de receitas para a sua execução é objeto imediato de preocupação. Este é justamente o fim do denominado federalismo fiscal: a coordenação das finanças públicas entre os entes federados ${ }^{22}$. Tal como no caso do conceito de federalismo, aqui também diversas teorias clássicas concorrem para a resolução da questão da organização da estrutura fiscal em vários níveis: a regra da proximidade, de George Stigler; a equivalência fiscal de Mancur Olson; a teoria da descentralização de Wallace Oats; e a teoria dos clubes de James Buchanan ${ }^{23}$. A estas teorias vêm somar-se novas contribuições como a de Shah Anwar; o modelo da accountability do Banco Mundial; e o modelo da New Public Governance ${ }^{24}$.

Todas estas abordagens seguem-se à secular teorização do princípio da subsidiariedade ${ }^{25}$, de acordo com o qual as funções financeiras (tributação, realização de despesas e regulação econômica) devem ser sempre exercidas pela menor "unidade social26", aquela situada ao nível da localidade na estrutura federal, exceto quando demonstrado razoavelmente que tais funções serão melhor realizadas pelos níveis superiores. De qualquer modo, uma garantia mínima de autonomia na imposição de tributos - o que parece estar no cerne da constituição fiscal ${ }^{27}$ - é constitutiva da própria noção de federalismo ${ }^{28}$.

Idealmente, a distribuição do poder fiscal deve ser precedida de uma avaliação dos gastos que serão suportados por cada ente, sendo três as formas de sua repartição ${ }^{29}$ : a atribuição exclusiva de receita tributária (exclusive tax assignment), a atribuição concorrente (concurency) e a previsão de mecanismos de repartição de receitas (tax sharing). Como se verá adiante, no Brasil o constituinte de 1988 empregou técnica mista, conjugando as três formas ${ }^{30}$.

better than these governments." BRETON, Albert. Modelling vertical competition. In: AHMAD, Ehtisham; BROSIO, Giorgio. (eds.). Handbook of Fiscal Federalism. Cheltenham: Edward Elgar, 2006. p. 92.

$22 \mathrm{MAJOCCHI}$, Alberto. Theories of Fiscal Federalism and the European Experience. In: WARD, Ann; WARD, Lee. (eds.). The Ashgate Research Companion to Federalism. Farnham: Ashgate, 2009. p. 425.

23 Para um resumo de cada uma destas teorias, remete-se o leitor a: SHAH, Anwar. Introduction: Principles of Fiscal Federalism. In: SHAH, Anwar. The Practice of Fiscal Federalism: Comparative Perspectives. Montréal: McGill-Queen's University Press, 2007. p. 07-09.

24 Para uma definição e breve discussão de cada uma destas teorias, veja-se: CABRAL, Nazaré da Costa. A teoria do federalismo financeiro. Coimbra: Almedina, 2015.

25 Para uma visão panorâmica das diferentes teorias filosóficas e econômicas da subsidiariedade, veja-se: FØLLESDAL, Andreas. Competing Conceptions of Subsidiarity. In: FLEMING, James E.; LEVY, Jacob T. Federalism and Subsidiarity. New York: New York University Press, 2014. e HUEGLIN, Thomas O. Federalism, Subsidiarity and the European Tradition: Some Clarifications. Telos, n. 100, p. 37-55, 1994. p. 46.

A aplicação do princípio a um esboço de justificação moral do federalismo no Brasil, pode ser vista em: BATISTA JÚNIOR, Onofre Alves; DE OLIVEIRA, Ludmila Mara Monteiro; MAGALHÃES, Tarcísio Diniz. Que pacto federativo? Em busca de uma teoria normativa adequada ao federalismo fiscal brasileiro. In: BATISTA JÚNIOR, Onofre Alves; MOREIRA, André Mendes. Estado federal e tributação: das origens à crise atual. Belo Horizonte: Arraes, 2015.

26 BARACHO, José Alfredo de Oliveira. O princípio de subsidiariedade: conceito e evolução. Revista da Faculdade de Direito da UFMG, n. 35, p. 13-52, 1996. p. 51.

27 "A fiscal constitution is the body of fundamental rules and regulations that frame decision making in the area of fiscal policy." BLÖCHLIGER, Hansjörg; KIM, Junghun. Fiscal Federalism: Making Decentralization Work. Paris: OECD Publishing, 2016. p. 32

28 RILKER, W. Federalism. In: GREENSTEIN, F.; POLSBY N. (eds.). The Handbook of Political Science: Government Institutions and Processes. Boston: Addison-Wesley Pub. Co., 1975.

Em sentido contrário, afirmando que a repartição de competências tributárias não é requisito do federalismo, apenas a repartição de receitas: SCHOUERI, Luís Eduardo. Direito tributário. São Paulo: Saraiva Educação, 2018. p. 258.

29 Para uma análise econômica dos princípios de repartição do poder de tributar, veja-se: HUEGLIN, Thomas 0.; FENNA, Alan. Comparative Federalism: A Systematic Inquiry. Toronto: University of Toronto Press, 2015. p. 166-204.

30 "In principle, the 1988 constitution established a relatively conventional mix of separate and concurrent tax assignment. In practice, the outcome shows the rather unconventional picture of a 'dual fiscal regime': states and municipalities acquired 'greater power to tax and a greater share of traditional revenues'; at the same time, the federal government was assigned 'a 
A partir dessas considerações teóricas, é necessário ressaltar que os Estados federais dificilmente brotam da pena dos intelectuais. São, pelo contrário, o resultado de enfrentamentos políticos, conflitos e convulsões sociais, distanciando-se expressivamente dos modelos ideais que derivam de uma reflexão ponderada. É com esse fato em mente que se deve passar à análise da repartição de competências e receitas tributárias constitutiva do federalismo fiscal brasileiro.

\section{A REPARTIÇÁO DE COMPETÊNCIAS E DE RECEITAS TRIBUTÁRIAS NA CONSTITUIÇÃO DE 1988: O FEDERALISMO FISCAL BRASILEIRO}

Como visto anteriormente, no plano ideal, recomenda a teoria econômica que a distribuição das competências administrativas, posto que relacionada ao âmbito orçamentário das despesas, preceda a distribuição das competências tributárias e de transferências governamentais, quando da criação da constituição fiscal ${ }^{31}$. Raramente isso se dá na prática e não foi diferente no caso brasileiro, cuja Constituição incorporou, com algumas modificações, o arcabouço tributário existente nas constituições anteriores ${ }^{32}$.

Ainda assim, a Constituição de 1988, inovou ao prever uma descentralização inaudita das fontes de receita, nítido reflexo da democratização por que passava o país quando de sua elaboração ${ }^{33}$, distribuindo tributos para aumentar a autonomia dos entes subnacionais. Mas este movimento não foi acompanhado por uma descentralização dos encargos que continuaram concentrados na União ${ }^{34}$. 0 resultado, que não poderia ser mais desastroso para a coordenação do nascente federalismo financeiro, foi a utilização expressiva da competência residual por parte da União ${ }^{35}$. Quaisquer que sejam, todavia, as razões históricas para este movimento, sob a perspectiva dogmática, tal prática mostra-se incompatível com a ordem

distinct set of compulsory levies' to finance social policy for all Brazilians." HUEGLIN, Thomas O.; FENNA, Alan. Comparative Federalism: A Systematic Inquiry. Toronto: University of Toronto Press, 2015. p. 203.

$31 \mathrm{SHAH}$, Anwar. Introduction: Principles of Fiscal Federalism. In: SHAH, Anwar. The Practice of Fiscal Federalism: Comparative Perspectives. Montréal: McGill-Queen's University Press, 2007. p. 19.

32 "Na história constitucional brasileira, o tema da discriminação de competências teve uma evolução marcada por um caráter muito mais empírico do que racional. Os impostos foram de incluindo em cada texto constitucional a partir de realidades preexistentes, sendo o elenco que se encontra no texto de 1988 mera distribuição de impostos que já se conheciam por vezes com pequenas modificações. Em outras palavras, o constituinte de 1988 tinha uma noção (tipológica) da existência de tributos e com eles trabalhou na previsão de recursos financeiros para o Estado." SCHOUERI, Luís Eduardo. A lei complementar e a repartição de competências tributárias. In: COSTA, Alcides Jorge. Sistema Tributário Nacional e a estabilidade da federação brasileira. São Paulo: Noeses, 2012. p. 680.

Para uma investigação histórica do federalismo no direito tributário brasileiro, veja-se: COSTA, Alcides Jorge. História da tributação no Brasil: da República à Constituição de 1988. In: SANTI, Eurico Marcos Diniz de. Curso de direito tributário e finanças públicas. São Paulo: Saraiva, 2008

33 Como ressalta Misabel Derzi, o federalismo relaciona-se de perto com a democracia: "[...] o federalismo é uma descentralização do poder, guardando íntima relação com a democracia. Não se nega a possibilidade de a forma unitária de Estado conviver com regimes políticos que adotem o princípio democrático, mas a descentralização do poder peculiar à forma federal de estado acarreta mais facilmente a república democrática." DERZI, Misabel de Abreu Machado. Direito tributário, direito penal e tipo. São Paulo: Editora Revista dos Tribunais, 2007. p. 117.

34 Para uma investigação mais abrangente da história do federalismo no Brasil, veja-se: OLIVEIRA, Fabrício Augusto. Teorias da federação e do federalismo fiscal: o caso brasileiro. Texto para discussão n. 43. Belo Horizonte: Fundação João Pinheiro, 2007

35 OLIVEIRA, Fabrício Augusto; CHIEZA, Rosa Angela. Auge e declínio da federação brasileira: 1988-2017. In: ANFIP; FENAFISCO. A Reforma Tributária Necessária: diagnóstico e premissas. Brasília/São Paulo: Plataforma Política Social, 2018. 
constitucional em vigor, como será demonstrado adiante. Antes de se passar, todavia, a uma avaliação crítica desta prática, é necessário apresentar a estrutura da repartição de competências tributárias na Constituição de 1988 que é, como se sabe, e em decorrência do federalismo, rígida ${ }^{36}$.

Como ensina Sacha Calmon, a competência corresponde à divisão constitucional ${ }^{37}$ do poder de tributar - "[...] originariamente uno por vontade do povo [...] $]^{38 " ~-~ e n t r e ~ a s ~ p e s s o a s ~}$ jurídicas de direito público interno que, no Brasil, são a União, os Estados, o Distrito Federal e os Municípios ${ }^{39}$. Esta não se confunde, portanto, com a competência para legislar sobre direito tributário - concorrente, segundo impõe o art. 24, CR, cabendo à União legislar sobre normas gerais - tampouco com a capacidade tributária ativa que é a aptidão delegável de arrecadar tributos. Como ensina de longa data a doutrina nacional, a competência tributária é dotada das características da privatividade, indelegabilidade, incaducabilidade, inalterabilidade, irrenunciabilidade e facultatividade ${ }^{40}$.

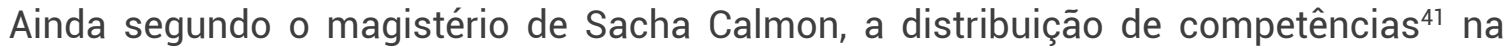
Constituição de 1988 segue um critério que resulta da coordenação do conceito de competência privativa (exclusiva) ${ }^{42}$ e de competência comum cumulado à teoria da vinculação da hipótese de incidência ${ }^{43}$, esta última disseminada no Brasil por Geraldo Ataliba ${ }^{44}$. É assim que os tributos vinculados a uma atuação estatal dizem-se de competência comum, isto é, podem ser instituídos por quaisquer dos entes federados, desde que estes sejam competentes administrativamente para a prática do ato que se associa à pessoa do contribuinte (prestação de serviço público específico e divisível ou exercício do poder de polícia, no caso das taxas; e realização de obra pública da qual decorra valorização imobiliária, no caso das contribuições de melhoria). Como a competência tributária nestes casos liga-se à competência administrativa, afirma-se, com espeque na literatura alemã, tratar-se de competência anexa ${ }^{45}$.

No caso dos tributos não vinculados a uma atuação estatal, a repartição se dá com base no estabelecimento prévio dos fatos geradores que são, em seguida, distribuídos entre as pessoas jurídicas de direito público interno (impostos, empréstimos compulsórios e contribuições especiais). Assim é que à União cabe instituir, além dos empréstimos compulsórios

36 BALEEIRO, Aliomar. Uma introdução à ciência das finanças. Atualização de Hugo de Brito Machado Segundo. Rio de Janeiro: Forense, 2015. p. 291.

37 Como lembra Humberto Ávila, para a determinação da competência tributária concorrem também as leis complementares. ÁVILA, Humberto. Sistema constitucional tributário. São Paulo: Saraiva, 2010. p. 141-142.

38 COÊLHO, Sacha Calmon Navarro. Curso de direito tributário brasileiro. Rio de Janeiro: Forense, 2018. p. 47.

39 Ao contrário do que se passa, por exemplo, na Argentina, no Brasil o poder de tributar concedido aos Municípios é originário e não derivado. Sobre a classificação do poder tributário em originário e derivado, veja-se: FONROUGE, Giuliani. Derecho financiero. Buenos Aires: La Ley, 2004. p. 267-270.

40 Para uma definição de cada uma destas características, veja-se: CARRAZZA, Roque Antonio. Curso de direito constitucional tributário. São Paulo: Malheiros, 1999. p. 339-431.

41 Como quer a melhor doutrina, a Constituição não cria tributos, quem o faz é a pessoa constitucionalmente competente, mediante lei de sua lavra. BALEEIRO, Aliomar. Direito tributário brasileiro. Atualizado por Misabel de Abreu Machado Derzi. Rio de Janeiro: Forense, 2013. p. 38.

42 Emprega-se aqui a denominação privativa, porque estabelecida na literatura tributária brasileira. Todavia, na teoria constitucional a modalidade de competência que não admite delegação é denominada exclusiva.

43 COÊLHO, Sacha Calmon Navarro. Curso de direito tributário brasileiro. Rio de Janeiro: Forense, 2018. p. 51.

44 ATALIBA, Geraldo. Hipótese de incidência tributária. São Paulo: Malheiros, 2013.

45 As competências administrativas na Constituição de 1988 estão dispostas nos arts. 21, 22 (União), art. 25, § $1^{\circ}$ (competência residual dos Estados), art. 30 (Municípios) e art. $32, \S 1^{\circ}$ (competência dúplice do Distrito Federal). 
e das contribuições especiais ${ }^{46}$, os impostos previstos no art. 153; aos Estados aqueles previstos no art. 155; aos Municípios os arrolados no art. 156; e, finalmente, ao Distrito Federal cabem simultaneamente os impostos previstos nos arts. 155 e 156. Sob a perspectiva do contribuinte, que não será objeto de desenvolvimento neste trabalho, a discriminação de competências visa a preservar a capacidade contributiva, evitando múltiplas incidências sobre um mesmo fato gerador.

Além da classificação em privativa e comum, a literatura identifica também a competência residual e a extraordinária. Ambas cabem exclusivamente à União - o que demonstra o caráter centralizador do federalismo fiscal brasileiro - sendo a última a competência para instituir impostos extraordinários de guerra (art. 154, II, CR). A competência residual, por seu turno, desdobra-se no alcance de duas espécies tributárias - impostos e contribuições sociais $^{47}$ - devendo ser exercida nos limites contidos nos artigos 154, I, CR e 195, $\S 4^{\circ}, \mathrm{CR}$.

A previsão de competência residual no Brasil remete à Constituição de 193448. Nos moldes atuais, em que cabe com exclusividade à União, sendo indelegável a outros entes, a Constituição prevê requisitos rigorosos para o seu exercício. Segundo o art. 154, I, CR, para instituir impostos residuais, a União deve valer-se de lei complementar, cuidando para que a nova exação não possua fato gerador ou base de cálculo própria daqueles impostos já previstos no texto constitucional.

No caso das contribuições sociais residuais, os requisitos remetem àqueles contidos no artigo 154, I, CR, motivo pelo qual instalou-se celeuma relativa à determinação do comando normativo mirado pela Constituição. As contribuições residuais deveriam atender à literalidade dos requisitos postos no artigo 154, I, CR? Isto é, deveriam ser instituídas mediante lei complementar, ser não cumulativas e não possuir fato gerador ou base de cálculo própria dos impostos previstos na Constituição? Ou, mais especificamente, o artigo 194, $\S 4^{\circ}, \mathrm{CR}$, ao remeter ao artigo 154, I, CR, teria também o propósito de proibir a coincidência de base de cálculo de eventual contribuição residual com aquela dos impostos previstos na Constituição, a exemplo da restrição similar relativa às taxas (artigo $145, \S 2^{\circ}, \mathrm{CR}$ )? Segundo o Supremo Tribunal Federal, a resposta é negativa ${ }^{49}$. Assim, a instituição de novas contribuições para financiamento da seguridade social deve se dar mediante lei complementar (primeiro requisito), bastando que o legislador evite a coincidência do "fato gerador" e da base de cálculo com o de outras contribuições existentes ${ }^{50}$ (segundo requisito).

46 Exceção são as contribuições sociais estaduais, municipais e distritais instituídas para financiar o regime previdenciário de seus servidores públicos, com fundamento no art. $149, \S 1^{\circ}, \mathrm{CR}$.

47 Para o regime jurídico das contribuições sociais, veja-se: LOBATO, Valter. 0 regime jurídico-constitucional das contribuições destinadas ao custeio da seguridade social: a importância basilar e estruturante da finalidade e os demais limites ao poder de tributar. 2014. Tese (Doutorado em Direito) - Faculdade de Direito, Universidade Federal de Minas Gerais, Belo Horizonte.

Veja-se também: SPAGNOL, Werther Botelho. As contribuições sociais no direito brasileiro. Rio de Janeiro: Forense, 2002.

48 Para um breve histórico, veja-se: SCHOUERI, Luís Eduardo. Direito tributário. São Paulo: Saraiva Educação, 2018. p. 265268.

49 "[...] quando o $\S 4^{\circ}$, do art. 195, da C.F. manda obedecer a regra da competência residual da União - art. 154, I - não estabelece que as contribuições não devam ter fato gerador ou base de cálculo de impostos. As contribuições, criadas na forma do $\S 4^{\circ}$, do art. 195, da C.F., não deve ter, isto sim, fato gerador e base de cálculo próprios das contribuições já existentes." A decisão encontra-se assim ementada: CONSTITUCIONAL. TRIBUTÁRIO. PREVIDENCIÁRIO. CONTRIBUIÇÕES SOCIAIS: EMPRESÁRIOS. AUTÔNOMOS E AVULSOS. Lei Complementar $n^{\circ}$ 84, de 18.01.96: CONSTITUCIONALIDADE. I. - Contribuição social instituída pela Lei Complementar ${ }^{\circ}$ 84, de 1996: constitucionalidade. II. - R.E. não conhecido. BRASIL. Recurso Extraordinário n² 228.321-RS. Plenário. Rel. Ministro Carlos Velloso, D.J. 20.05.2003.

50 Vejam-se, por todos, os seguintes acórdãos: BRASIL. Recurso Extraordinário n 177.137-RS. Plenário. Rel. Ministro Moreira Alves, D.J. 03.05.1996. BRASIL. Recurso Extraordinário nº 165.939-RS. Plenário. Rel. Ministro Moreira Alves, D.J. 
No que diz respeito à partilha de receitas - "[...] principal forma de redistribuição interna de riquezas entre as unidades da federação brasileira ${ }^{51 "}$ - encontram-se na Constituição de 1988 duas formas de repartição do produto da arrecadação52: a direta (simples) - por meio da qual um ente acessa diretamente parcela da receita auferida por outro - e a indireta (complexa), mediante a qual os recursos arrecadados são remetidos a fundos para posterior partilha entre os seus integrantes segundo critérios estabelecidos em lei ${ }^{53}$. Verifica-se na Constituição apenas a modalidade de partilha vertical de receitas - aquela que "[...] ocorre do ente maior para o menor [...] ${ }^{54 "}$, ou seja, da União para os Estados ou para os Municípios e dos Estados para os Municípios - não se encontrando no direito brasileiro as denominadas repartições horizontais - aquelas que se dão dos entes mais ricos em favor das unidades mais pobres de uma federação - verificadas no direito australiano e alemão ${ }^{55}$.

Peculiaridade da constituição fiscal brasileira é o fato de que as contribuições residuais, diferentemente dos impostos residuais, não se sujeitam ao esquema de partilha de receitas. A exceção não deve causar espanto, em primeiro lugar, porque as contribuições são tributos cujo produto da arrecadação é vinculado ao atendimento de certas finalidades eleitas pela Constituição. Em segundo lugar e como mencionado anteriormente, a descentralização dos recursos promovida pela Constituição de 1988, não se fez acompanhar de uma efetiva descentralização dos encargos financeiros.

Ocorre que esta concentração de encargos na União, somada ao regime mais rigoroso para instituição de novos impostos e à necessidade de partilha do produto de sua arrecadação com os demais entes federados, resultou na utilização recorrente da competência residual para instituir novas contribuições o que, acompanhado do mecanismo de desvinculação de receitas criado pela Emenda Constitucional $n^{\circ} 27$, de 2000, acabou por enviesar ainda mais a constituição fiscal a seu favor ${ }^{56}$. Atentando-se para a perspectiva funcional,

03.05.1996; ; e BRASIL. Recurso Extraordinário n 228.321-RS. Plenário. Rel. Ministro Carlos Velloso, D.J. 20.05.2003.

51 MOREIRA, André Mendes. O Federalismo Brasileiro e a Repartição de Receitas Tributárias. In: MOREIRA, André Mendes; DERZI, Misabel de Abreu Machado; BATISTA JÚNIOR, Onofre Alves. (orgs.). Estado federal e tributação: das origens à crise atual. Belo Horizonte: Arraes Editores, 2015. p. 169.

52 Para uma análise exaustiva da repartição de receitas na Constituição de 1988, incluindo suas classificações em obrigatórias e voluntárias, vinculadas e não vinculadas, além das diretas e indiretas, veja-se: MOREIRA, André Mendes. O Federalismo Brasileiro e a Repartição de Receitas Tributárias. In: MOREIRA, André Mendes; DERZI, Misabel de Abreu Machado; BATISTA JÚNIOR, Onofre Alves. (orgs.). Estado federal e tributação: das origens à crise atual. Belo Horizonte: Arraes Editores, 2015.

53 COÊLHO, Sacha Calmon Navarro. Curso de direto tributário brasileiro. Rio de Janeiro: Forense, 2018. p. 286.

54 MOREIRA, André Mendes. O Federalismo Brasileiro e a Repartição de Receitas Tributárias. In: MOREIRA, André Mendes; DERZI, Misabel de Abreu Machado; BATISTA JÚNIOR, Onofre Alves. (orgs.). Estado federal e tributação: das origens à crise atual. Belo Horizonte: Arraes Editores, 2015. p. 158.

55 "With the notable exception of the United States, therefore, most federal systems have established fiscal equalization programs. Only some federations such as Germany, Canada, and Switzerland have written an obligation to fiscal equalization into their constitutions - thus acknowledging it as part of the basic compact of federal union. Such a constitutional obligation, however, is not an automatic indication of the degree to which equalization may actually be practised. While Germany has one of the most comprehensive systems of equalization, so does Australia-where no constitutional requirement for horizontal redistribution exists at all." HUEGLIN, Thomas O.; FENNA, Alan. Comparative Federalism: A Systematic Inquiry. Toronto: University of Toronto Press, 2015. p. 172.

56 "O padrão de ajuste que o governo federal adotou a partir dessa realidade e do qual não abriu mão até os dias atuais tornou-se perverso tanto para a estrutura tributária como para o crescimento econômico e para a própria federação. Por serem em geral de natureza cumulativa, à medida que incidem sobre o faturamento, a receita bruta ou a folha de salários, o maior avanço das contribuições sociais na estrutura tributária pioraria a qualidade do sistema de impostos, ao mesmo tempo em que comprometeria o princípio da competitividade ao onerar, mais que os impostos sobre o valor agregado, a produção nacional. No tocante à federação, porque a prioridade que se passou a dar à sua cobrança enfraqueceria, em termos relativos, a arrecadação dos impostos tradicionais, especialmente do IR e do IPI, diminuindo a participação relativa das esferas subnacionais no bolo tributário e revertendo os objetivos perseguidos com a reforma tributária da Constituição de modificar a equação da repartição federativa das receitas." OLIVEIRA, Fabrício Augusto; CHIEZA, Rosa Angela. Auge e declínio da federação brasileira: 1988-2017. In: ANFIP; FENAFISCO. A Reforma Tributária Necessária: diagnóstico e premissas. Brasília/São Paulo: Plataforma Política Social, 2018. p. 565-566. 
verifica-se, não obstante, que os requisitos para o exercício da competência residual devem ser buscados em uma interpretação sistemática da Constituição, o que implica reconhecer que o seu exercício está condicionado também a outros requisitos além daqueles nominalmente previstos no artigo 195, $\S 4^{\circ} \mathrm{c} / \mathrm{c} 154, \mathrm{I}, \mathrm{CR}$, como se verá a seguir.

\section{O INFLUXO DO FEDERALISMO NO MANDAMENTO DE CONFORMIDADE FUNCIONAL NA INTERPRETAÇÃO DA CONSTITUIÇÃO}

Tradicionalmente, o mandamento da conformidade funcional tem sido compreendido como uma norma que diz respeito à preservação do princípio da Separação de Poderes ${ }^{57}$. Aduzem os autores que se debruçaram sobre este princípio que a Constituição deve ser interpretada de modo a que a norma construída pelo intérprete preserve o esquema de repartição de incumbências previsto em seu texto. É dizer que a Constituição estabelece uma distribuição de encargos e, ao fazê-lo, sinaliza "[...] a vocação de cada um dos órgãos do Estado, o tipo de legitimação que caracteriza suas decisões, bem como as capacidades institucionais que reúne $[\ldots]^{58} . "$

$\mathrm{Na}$ formulação clássica de Konrad Hesse, o princípio, que se denomina "critério da exatidão funcional" volta-se sobretudo para uma restrição da atividade criadora da Corte Constitucional, exigência paralela àquela da legalidade e da Separação de Poderes que recomenda reverência à atividade legislativa, pois esta última seria o locus privilegiado da criação normativa ${ }^{59}$. Alargando a extensão semântica do princípio, José Canotilho afirma a sua incidência também nas "[...] relações verticais do poder (Estado/regiões, Estado/autarquias locais) 60", o que faria deste um princípio intimamente ligado à distribuição de competências no sentido exposto neste trabalho (descentralização de poder entre entes autônomos). Este desdobramento é especialmente relevante nos Estados que assumem a forma federativa, como é o caso do Brasil.

O federalismo, enquanto norma estruturante do sistema jurídico brasileiro, obriga a adequar-se o princípio da conformidade funcional à sua força normativa. É que, como rememora Sacha Calmon, citando o Digesto, na epígrafe de sua festeja obra: "incivile est, nisi lege prospecta, una aliqua partícula ejus proposita, judicare, vel respondere ${ }^{61 "}$ - isto é, o caráter

57 Para um exemplo desta abordagem, veja-se: SOUZA NETO, Cláudio Pereira de; SARMENTO, Daniel. Direito constitucional: teoria, história e métodos de trabalho. Belo Horizonte: Fórum, 2012. p. 1212. ed. eletr.

58 SOUZA NETO, Cláudio Pereira de; SARMENTO, Daniel. Direito constitucional: teoria, história e métodos de trabalho. Belo Horizonte: Fórum, 2012. p. 1212. ed. eletr.

59 "Um princípio da interpretação constitucional é o critério da exatidão funcional. Se a Constituição ordena a respectiva tarefa e a colaboração dos titulares de funções estatais em uma determinada forma, então o órgão interpretador tem de manter-se no quadro das funções a ele atribuídas; ele não deve, pela maneira e pelo resultado de sua interpretação, remover a distribuição das funções. Em especial, isso vale para a relação entre legislador e Tribunal Constitucional: como ao Tribunal cabe, diante do legislador, somente uma função controladora, é negada a ele uma interpretação que iria conduzir a uma limitação da liberdade conformadora do legislador mais além dos limites traçados pela Constituição ou a uma configuração por meio do tribunal mesmo." HESSE, Konrad. Elementos de direito constitucional da República Federal da Alemanha. Porto Alegre: Sergio Antonio Fabris Editor, 1998. p. 67.

60 CANOTILHO, José J. G. Direito constitucional e teoria da constituição. Coimbra: Almedina, 2011. p. 1225.

61 Na tradução do autor: "É contra o Direito julgar ou responder sem examinar o texto em conjunto, apenas considerando uma parte qualquer do mesmo." COÊLHO, Sacha Calmon Navarro. Curso de direto tributário brasileiro. Rio de Janeiro: Forense, 
sistemático do direito não pode ser olvidado quando da interpretação de qualquer de seus elementos.

Nas federações, o princípio da conformidade funcional demanda também que a Constituição seja interpretada de modo a se preservar as competências outorgadas aos entes subnacionais. Como amparo em Friedrich Müller, pode-se afirmar que o mandamento da correção funcional, torna o federalismo relevante com vistas ao próprio método de interpretação constitucional62. Nesta toada, a interpretação dos dispositivos que compõem a Constituição fiscal brasileira - quais sejam, os artigos referentes ao Sistema Tributário Nacional e à repartição de receitas tributárias - deve se dar sob a ótica da partilha de poder estabelecida pelo princípio federal. Ora, como afirma Valter Lobato, recordando Ataliba, “[...] os princípios que devem nortear o Ordenamento Jurídico Pátrio, via de consequência, o próprio Sistema Tributário, são o Federalismo e a separação de poderes na preservação do Estado Democrático de Direito. ${ }^{63 "}$

É necessário, entretanto, cautela, pois a competência residual, prevista em duas ocasiões no texto constitucional, cabe induvidosamente à União, não sendo passível de qualquer admoestação o seu exercício de per si. Muito antes pelo contrário, a criação de novos tributos (impostos e contribuições sociais) é prerrogativa da pessoa jurídica de direito público interno a quem a Constituição atribuiu tal possibilidade, consistindo em importante elemento de sua estrutura fiscal, indissociável, portanto, de sua autonomia política. A despeito de sua natural conformidade com o texto constitucional, o exercício da competência residual não pode "[...] alterar a distribuição constitucionalmente normatizada [...] $]^{64 "}$ de poder entre as unidades da Federação. É dizer que a concretização da Constituição ${ }^{65}$ deve inexoravelmente levar em conta o equilíbrio das relações de poder entre os entes federados.

\section{O EXERCÍCIO DA COMPETÊNCIA RESIDUAL POR PARTE DA UNIÁO E A PERTURBAÇÃO DO MODELO CONSTITUCIONAL DE REPARTIÇÃO DE COMPETÊNCIAS}

Como visto acima, a concretização de qualquer norma constitucional deve levar em conta o esquema primordial de repartição de competências no qual aquela norma está inserida. A interpretação de texto relativo à competência tributária não pode resultar na construção de norma que atente contra a própria distribuição de competências. Eventualmente, exercício formalmente adequado e aparentemente legítimo de competência tributária, pode afrontar a Constituição. É neste momento que se faz relevante o mandamento de conformi-

2018. (epígrafe)

62 MÜLLER, Friedrich. Métodos de trabalho no direito constitucional. Rio de Janeiro: Renovar, 2005. p. 139.

63 LOBATO, Valter de Souza. O custeio da seguridade social e os benefícios de risco: os princípios aplicáveis e os limites ao poder de tributar. In: DERZI, Misabel de Abreu Machado (org.). Separação de poderes e efetividade do sistema tributário. Belo Horizonte: Del Rey, 2010. p. 433.

64 MÜLLER, Friedrich. Métodos de trabalho no direito constitucional. Rio de Janeiro: Renovar, 2005. p. 139. 
dade funcional, pois ao introduzir o federalismo como uma consideração de método, revela os limites internos do exercício desta modalidade de outorga do poder de tributar.

Como já se pronunciou o Supremo Tribunal Federal no Ag.Reg. RE nº 793564-PE, a mera desvinculação de receitas da União não tem o condão de transmutar em imposto as contribuições sociais:

CONTRIBUIÇÃO SOCIAL - RECEITAS - DESVINCULAÇÃO - ARTIGO 76 DO ATO DAS DISPOSIÇÕES CONSTITUCIONAIS TRANSITÓRIAS - EMENDAS CONSTITUCIONAIS N 27, DE 2000 E N 42, DE 2003 - MODIFICAÇÃO NA APURAÇÃO DO FUNDO DE PARTICIPAÇÃO DOS MUNICÍPIOS. A desvinculação parcial da receita da União, constante do artigo 76 do Ato das Disposições Constitucionais Transitórias, não transforma as contribuições sociais e de intervenção no domínio econômico em impostos, alterando a essência daquelas, ausente qualquer implicação quanto à apuração do Fundo de Participação dos Municípios. Precedente: Ação Direta de Inconstitucionalidade $n^{\circ}$ 2.925/DF, em que fui designado redator para o acórdão. MULTA - AGRAVO - ARTIGO 557, § $2^{\circ}$, DO CÓDIGO DE PROCESSO CIVIL. Surgindo do exame do agravo o caráter manifestamente infundado, impõe-se a aplicação da multa prevista no $\S 2^{\circ}$ do artigo 557 do Código de Processo Civil. ${ }^{66}$

De fato, o que se atinge por vias transversas com o uso reiterado deste instrumento não é propriamente a natureza das contribuições, cujo recurso estaria agora parcialmente desafetado, mas sim a equalização fiscal, que é componente normativo da forma federativa de Estado no Brasil. Analisando-se a questão superficialmente - isto é, considerando-se exclusivamente o ângulo formal da atribuição de competências e da repartição de receitas -, de fato não caberia cogitar da participação de Estados ou Municípios no recurso arrecadado com estes tributos. É o que conclui o Supremo Tribunal no acórdão do Recurso Extraordinário $n^{\circ}$ 537.610/RS de lavra do Ministro Cezar Peluso, assim ementado:

TRIBUTO. Contribuição social. Art. 76 do ADCT. Emenda Constitucional $n^{\circ}$ $27 / 2000$. Desvinculação de $20 \%$ do produto da arrecadação. Admissibilidade. Inexistência de ofensa a cláusula pétrea. Negado seguimento ao recurso. Não é inconstitucional a desvinculação de parte da arrecadação de contribuição social, levada a efeito por emenda constitucional. ${ }^{67}$

No mesmo sentido, o posicionamento exarado pelo Supremo Tribunal no Recurso Extraordinário $\mathrm{n}^{0} 566.007 / \mathrm{RS}^{68}$. Como visto anteriormente, segundo a melhor literatura, a compe-

66 "A desvinculação parcial da receita da União, constante no referido artigo 76 do Ato das Disposições Constitucionais Transitórias, não transforma as contribuições sociais e de intervenção no domínio econômico em impostos, alterando a essência daquelas." BRASIL. Agravo Regimental no Recurso Extraordinário nº 793564-PE. Plenário, Rel. Ministro Marco Aurélio, DJe 01.10 .2014

67 BRASIL. Recurso Extraordinário n 537.610/RS. Plenário. Rel. Ministro Cezar Peluso, DJ 18.12.2009.

68 A decisão encontra-se assim ementada: DIREITOS CONSTITUCIONAL E TRIBUTÁRIO. REPERCUSSÃO GERAL. DESVINCULAÇÃO DE RECEITAS DA UNIÃO - DRU. ART. 76 DO ATO DAS DISPOSIÇÕES CONSTITUCIONAIS TRANSITÓRIAS. AUSÊNCIA DE CORRELAÇÃO ENTRE A ALEGADA INCONSTITUCIONALIDADE DA DRU E O DIREITO À DESONERAÇÃO TRIBUTÁRIA PROPORCIONAL À DESVINCULAÇÃO. ILEGITIMIDADE PROCESSUAL. AUSÊNCIA DE DIREITO LÍQUIDO E CERTO. RECURSO EXTRAORDINÁRIO AO QUAL SE NEGA PROVIMENTO. 1. A questão nuclear deste recurso extraordinário não é se o art. 76 do ADCT ofenderia norma permanente da Constituição da República, mas se, eventual inconstitucionalidade, conduziria a ter a Recorrente direito à desoneração proporcional à desvinculação das contribuições sociais recolhidas. 2. Não é possível concluir que, eventual inconstitucionalidade da desvinculação parcial da receita das contribuições sociais, teria como consequência a devolução ao contribuinte do montante correspondente ao percentual desvinculado, pois a tributação não seria inconstitucional ou ilegal, única hipótese autorizadora da repetição do indébito tributário ou o reconhecimento de inexistência de relação jurídico-tributária. 3. Não tem legitimidade para a causa o contribuinte que pleiteia judicialmente a restituição ou o não recolhimento proporcional à desvinculação das receitas de contribuições sociais instituída pelo art. 76 do ADCT, tanto em sua forma originária quanto na forma das alterações promovidas pelas Emendas Constitucionais n. $27 / 2000,42 / 2003,56 / 2007,59 / 2009$ e $68 / 2011$. Ausente direito líquido e certo para a impetração de mandados de 
tência deve ser compreendida como um arranjo em rede, de cujo equilíbrio dependem todos os entes federados. No Brasil, a forma federativa de Estado, enunciada já no artigo inaugural da Constituição, nos termos do seu artigo $60, \S 4^{\circ}$, I, não pode ser abolida sequer por emenda constitucional. É assim que o programa normativo relativo à competência residual esbarra no limite textual explícito ${ }^{69}$ da forma federada de Estado que é, simultaneamente, elemento relevante em relação ao método para concretização e em relação ao conteúdo da norma jurídica, o que foi ignorado pelo STF iterativamente:

Foram as Emendas Constitucionais n ${ }^{\circ} 27 / 2000$ e $n^{\circ} 42 / 2003$ que, alterando o art. 76 do Ato das Disposições Constitucionais Transitórias, determinaram a desvinculação das receitas de impostos e contribuições sociais da União e sua aplicação na Conta Única do Tesouro Nacional, sem que aqui desponte incompatibilidade com o restante do texto constitucional. Ademais, é de se observar que a norma que determina a vinculação da destinação do produto da arrecadação das contribuições sociais não assume caráter de cláusula pétrea, uma vez não contemplada pelo art. $60, \S 4^{\circ}$, da Constituição Federal [...]. Destarte, nada impede que Emenda Constitucional estatua desvinculação de receitar, como fizeram as Emendas Constitucionais n 27/200 e 42/2003. ${ }^{70}$

É dizer, para verificar se o exercício da competência residual está em conformidade com a Constituição, não pode o intérprete se limitar a uma leitura "fria" do art. $60, \S 4^{\circ}$, para constatar que a vinculação dos recursos arrecadados é cláusula passível de modificação pelo poder constituinte derivado. Para se identificar o programa da norma em questão, não é suficiente investigar a compatibilidade formal do ato de exercício da competência com o esquema de repartição previsto na Constituição (legitimidade formal) ou a sua eventual flexibilidade no texto da constituição. É necessário, ainda, que o intérprete verifique se o seu exercício é compatível com a norma superior (mais genérica) que orienta aquela repartição, donde a aplicabilidade do critério da conformidade funcional.

Ao prever a competência residual tanto para a instituição de impostos quanto para a instituição de contribuições sociais, a norma em questão enlaça o exercício da competência residual ao alcance da finalidade atinente a esta importante espécie tributária - o financiamento da seguridade social. Não quis a Constituição, todavia, limitar a União, tendo Ihe concedido parcela da competência para a instituição de impostos, de modo a ampliar o seu espaço fiscal quando necessário. Naturalmente, a competência para a instituição de novos impostos visa a abastecer os cofres públicos de receita não afetada ${ }^{71}$, consequentemente disponível para financiar todos os demais encargos da União. Identifica-se, portanto, um

segurança. 4. Negado provimento ao recurso extraordinário. BRASIL. Recurso Extraordinário n 566.007/RS. Plenário. Rel. Ministra Cármen Lúcia, DJ 11.02.2015.

69 Segundo Riccardo Guastini, a interpretação constitucional sujeita-se a limites implícitos e explícitos. Estes últimos são "[...] aqueles expressamente estabelecidos pelo mesmo documento constitucional interpretado ao pé da letra." GUASTINI, Riccardo. Interpretar y argumentar. Madrid: Centro de Estudios Políticos y Constitucionales, 2014. p. 320. (trad. livre)

Para Friedrich Müller, a remissão da literatura positivista a limites semânticos fixados na literalidade dos vocábulos que compõem o texto normativo é ilusória. Todavia, toma-se neste trabalho o sentido da limitação como explícito não em vista de uma suposta enunciação linguística literal ("a forma federativa de Estado"), mas sim de sua previsão no texto normativo que se contrapõe a limites derivados da norma propriamente dita (após a sua concretização). Cf. MÜLLER, Friedrich. Teoria estruturante do direito. São Paulo: Revista dos Tribunais, 2008. p. 244 ss.

70 BRASIL. Recurso Extraordinário n 537.610/RS. Plenário. Rel. Ministro Cezar Peluso, DJ 18.12.2009.

71 Para uma reflexão em torno da relação do princípio da não-afetação da receita de impostos e o princípio da igualdade, veja-se: DERZI, Misabel Abreu Machado. O princípio da não afetação da receita de impostos e a justiça distributiva. HORVATH, Estevão; CONTI, José Maurício; SCAFF, Fernando Facury (Org.). Direito Financeiro, Econômico e Tributário: estudos em homenagem a Regis Fernandes de Oliveira. São Paulo: Quartier Latin, 2014. 
esquema singelo que corresponde ao aspecto teleológico da norma que condiciona o exercício da competência residual:

1) Diante da necessidade de obter recursos para financiar despesas com a seguridade social, deve a União instituir contribuições sociais residuais. Tendo em vista que o produto da arrecadação das contribuições é vinculado a despesas, não há que se cogitar da repartição da receita arrecadada com os demais entes federados, como quer a própria Constituição.

2) Diante da necessidade de obter recursos para financiar despesas gerais, previstas no orçamento fiscal, deve a União instituir impostos residuais. Neste caso, destinará obrigatoriamente $20 \%$ do produto arrecadado aos Estados e ao Distrito Federal, nos termos do artigo 157, II, CR.

A razão que se encontra por detrás deste esquema não é, todavia, pueril. Trata-se de preservar a equalização fiscal entre os entes federados, exigência da própria democracia que não tolera o desrespeito aos textos de normas remissíveis a vontade do povo (a forma federativa de Estado é exemplo) por parte dos próprios elementos constitutivos do Estado ${ }^{72}$. Ao instituir reiteradamente contribuições sociais, desvinculando o produto de sua arrecadação, para compor o orçamento fiscal, a União visa a elidir os requisitos previstos no artigo 154, I, CR.

Assim o fazendo, não apenas desequilibra irremediavelmente a constituição fiscal em seu favor, como, ao privar as demais unidades da Federação de recursos, limita o poder de ação destas, o que consiste em um atentado (indireto) à sua competência. É por este motivo que a utilização da competência residual tal como prevista no item 1 acima (instituição de contribuições sociais) para os fins contidos no item 2 (financiamento das despesas gerais da União) mostra-se incompatível com a Constituição de 1988, ainda que aparente legitimidade. Novamente, cabe invocar os ensinamentos de Sacha Calmon que, recordando a adjunção entre finalidade e competência nos tributos causais e finalísticos, afirma:

Não faz sentido a Constituição proibir a afetação de impostos a órgão, fundo, programa ou despesa (art. 167, IV) e submeter a severas limitações o exercício da competência residual para criar impostos e contribuições novas, além dos discriminados na Constituição, preservando assim o sistema de repartição das competências tributárias impositivas das pessoas políticas e, ao mesmo tempo, a doutrina e a jurisprudência, admitirem, à margem do sistema constitucional, a criação a la diable, de milhares de "contribuições interventivas" e sociais em sentido lato (fora do art. $195 \mathrm{da} \mathrm{CF}$ ) para os mais variados fins e que são, pela análise de seus fatos geradores, verdadeiros impostos instituídos por leis ordinárias. ${ }^{73}$

De fato, uma compreensão adequada da norma em questão orienta o intérprete no sentido de que a escolha pela utilização de uma ou de outra espécie residual não é pura e simples prerrogativa política da União. Como se sabe, cabe ao texto constitucional, nos Estados Democráticos de Direito, como ainda é o caso do Brasil, a normatização do processo político ${ }^{74}$. No presente caso, a necessária adequação da finalidade das receitas que serão auferidas com a espécie tributária que se pretende instituir representa um limite incontorná-

72 Neste sentido: MÜLLER, Friedrich. Métodos de trabalho no direito constitucional. Rio de Janeiro: Renovar, 2005. p. 140.

73 COÊLHO, Sacha Calmon Navarro. Contribuições no direito brasileiro: seus problemas e soluções. In: DERZI, Misabel de Abreu Machado (org.). Separação de poderes e efetividade do sistema tributário. Belo Horizonte: Del Rey, 2010. p. 430.

74 MÜLLER, Friedrich. Métodos de trabalho no direito constitucional. Rio de Janeiro: Renovar, 2005. p. 140. 
vel ao exercício da competência residual, sob a perspectiva da correção funcional. De outro modo, se estaria permitindo que a União modificasse unilateralmente, e por vias transversas, o padrão de repartição de receitas imposto pelo princípio do federalismo, o que consistiria em fraude à Constituição, em detrimento do próprio pacto federativo.

\section{CONCLUSÃO}

Como indica a revisão da literatura realizada neste trabalho, a multiplicidade de modelos de Estados federados existentes recomenda que se compreenda o federalismo mais como um princípio de organização política, isto é, como um tipo político, do que como um modelo ideal bem determinado. Neste sentido, como demonstramos, uma teoria adequada parece ser a de Daniel Elazar, para quem um sistema federal é um complexo em formato de rede, no qual os elementos encontram-se interligados por arranjos de interdependência.

Nos países que adotam o federalismo, a questão das finanças públicas torna-se premente, pois, para garantir a autonomia política dos entes subnacionais é preciso resguardar a sua autonomia financeira. Não por outro motivo é que a Constituição de 1988 procede, como visto, a uma minuciosa repartição de competências tributárias que se faz acompanhar de um mecanismo de redistribuição vertical de receitas. Neste arranjo, coube à União a possibilidade de instituir tributos outros, além daqueles previstos no texto originário da Constituição, fenômeno a que se denomina "competência residual". Esta pode ser utilizada para dar surgimento a impostos ou contribuições novas. No caso dos impostos residuais, a Constituição determina a repartição do produto de sua arrecadação com os Estados (art. 157, II, $\mathrm{CR}$ ), inexistindo regra similar relativamente às contribuições sociais residuais. É dizer que a Constituição não previu a partilha dos recursos auferidos com novas contribuições sociais eventualmente criadas pela União. A razão para tanto está na natureza deste tributo, cujo produto da arrecadação é vinculado a determinados fins constitucionalmente privilegiados, no caso, o financiamento da seguridade social. Não obstante a aparência de legitimidade, reconhecida inclusive pelo Supremo Tribunal Federal em mais de uma ocasião, a concretização da Constituição fiscal exige que se adote uma interpretação da competência residual conforme ao critério de correção funcional.

Como demonstramos neste trabalho, nos Estados federativos, o princípio de correção funcional, também chamado de mandamento de conformidade funcional, exige que o resultado da interpretação esteja em conformidade com a estrutura federal, isto é, com a divisão constitucional de competências. Com fundamento em Friedrich Müller, pode-se afirmar que este princípio transpõe o federalismo para ocupar espaço na própria metodologia de construção das normas constitucionais. É dizer que por força do critério de correção funcional, o federalismo torna-se relevante para o aplicador do direito em relação ao próprio método de abordagem do texto constitucional.

Esta influência dúplice do federalismo na construção da norma que cria a competência residual obriga a que se observem os seus limites internos. Assim, concluímos que o exercício da competência residual não pode ofender a equalização fiscal, componente inarredável da forma federativa de Estado no Brasil. Por este motivo, não basta verificar apenas a 
conformidade formal - seja na perspectiva da desvinculação de receitas, seja na da criação de novas contribuições sociais - ambos os fatos devem ser avaliados à luz da norma que orienta a própria distribuição de competência aos entes da Federação brasileira.Dessarte, como demonstrado neste trabalho, não se pode ignorar que, ao prever duas diferentes hipóteses de exercício de competência residual, a Constituição vincula a escolha de cada uma das hipóteses à destinação que se pretende dar aos recursos que serão arrecadados. Se o intuito é a obtenção de nova fonte de receita para o financiamento de despesas gerais, a União deverá utilizar-se da competência residual prevista no artigo 154, I, CR. Neste caso, impõe-se a repartição do produto arrecadado com os Estados, nos termos do art. 157, II, CR. Por outro lado, se o intuito é a obtenção de receitas para financiar a seguridade social, a União poderá utilizar-se da competência residual prevista no artigo $194, \S 4^{\circ}, \mathrm{CR}$, ocasião em que estará dispensada de qualquer obrigação relativa à repartição dos recursos. A conclusão que se depreende de uma interpretação conforme ao mandamento da correção funcional é a de que a opção pela criação de uma ou outra espécie residual não cabe à simples discricionariedade da União. A análise do princípio da correção funcional à luz do federalismo fiscal brasileiro demonstrou que a adequação da finalidade das receitas auferidas com a espécie tributária a ser instituída representa um limite objetivo ao exercício da competência residual.

\section{REFERENCIAS}

ALTHUSIUS, Johannes. Politics as the Art of Associating. In: JARMIS, Dimitrios; NORMAN, Wayne (eds.). Theories of Federalism: A Reader. New York: Palgrave MacMillan, 2005.

ATALIBA, Geraldo. Hipótese de incidência tributária. São Paulo: Malheiros, 2013.

ÁVILA, Humberto. Sistema constitucional tributário. São Paulo: Saraiva, 2010.

BALEEIRO, Aliomar. Direito tributário brasileiro. Atualizado por Misabel de Abreu Machado Derzi. Rio de Janeiro: Forense, 2013.

BALEEIRO, Aliomar. Uma introdução à ciência das finanças. Atualização de Hugo de Brito Machado Segundo. Rio de Janeiro: Forense, 2015.

BARACHO, José Alfredo de Oliveira. O princípio de subsidiariedade: conceito e evolução. Revista da Faculdade de Direito da UFMG, n. 35, p. 13-52, 1996.

BARACHO, José Alfredo de Oliveira. Teoria geral do federalismo. Rio de Janeiro: Forense, 1986.

BATISTA JÚNIOR, Onofre Alves; DE OLIVEIRA, Ludmila Mara Monteiro; MAGALHÃES, Tarcísio Diniz. Que pacto federativo? Em busca de uma teoria normativa adequada ao federalismo fiscal brasileiro. In: BATISTA JÚNIOR, Onofre Alves; MOREIRA, André Mendes. Estado federal e tributação: das origens à crise atual. Belo Horizonte: Arraes, 2015.

BLÖCHLIGER, Hansjörg; KIM, Junghun. Fiscal Federalism: Making Decentralization Work. Paris: OECD Publishing, 2016.

BOADWAY, Robin; SHAH, Anwar. Fiscal Federalism: Principles and Practices of Multiorder Governance. Cambridge: Cambridge University Press, 2009.

BRASIL. Constituição da República Federativa do Brasil de 1988. Disponível em: http://www.planalto.gov.br/ccivil_03/constituicao/constituicao.htm. Acesso em: 12 ago. 2018.

BRASIL. Emenda Constitucional n 27, de 2000. Acrescenta o art. 76 ao Ato das Disposições Constitucionais Transitórias, instituindo a desvinculação de arrecadação de impostos e contribuições sociais da União. Dis- 
ponível em: http://www2.camara.leg.br/legin/fed/emecon/2000/emendaconstitucional-27-21-marco-2000-373981-publicacaooriginal-1-pl.html. Acesso em: 08 ago. 2018.

BRASIL. Emenda Constitucional n 42, de 2003. Altera o Sistema Tributário Nacional e dá outras providências. Disponível em: http://www2.camara.leg.br/legin/fed/emecon/2003/emendaconstitucional-42-19-dezembro-2003-497205-norma-pl.html. Acesso em: 08 ago. 2018.

BRASIL. Emenda Constitucional n 56, de 2007. Prorroga o prazo previsto no caput do art. 76 do Ato das Disposições Constitucionais Transitórias e dá outras providências. Disponível em: http://www2.camara.leg.br/legin/fed/ emecon/2007/emendaconstitucional-56-20-dezembro-2007-567249-norma-pl.html. Acesso em: 08 ago. 2017.

BRASIL. Emenda Constitucional n 68, de 2011. Altera o art. 76 do Ato das Disposições Constitucionais Transitórias. Disponível em: http://www2.camara.leg.br/legin/fed/emecon/2011/emendaconstitucional-68-21-dezembro-2011-612061-publicacaooriginal-134728-pl.html. Acesso em: 08 ago. 2018.

BRASIL. Emenda Constitucional No 93, de 2016. Altera o Ato das Disposições Constitucionais Transitórias para prorrogar a desvinculação de receitas da União e estabelecer a desvinculação de receitas dos Estados, Distrito Federal e Municípios. Disponível em: http://www2.camara.leg.br/legin/fed/emecon/2016/emendaconstitucional-93-8-setembro-2016-783591-publicacaooriginal-151044-pl.html. Acesso em: 08 ago. 2018.

BRASIL. Recurso Extraordinário n 165.939-RS. Plenário. Rel. Ministro Moreira Alves, D.J. 03.05.1996.

BRASIL. Recurso Extraordinário n 177.137-RS. Plenário. Rel. Ministro Moreira Alves, D.J. 03.05.1996.

BRASIL. Recurso Extraordinário n²28.321-RS. Plenário. Rel. Ministro Carlos Velloso, D.J. 20.05.2003.

BRASIL. Agravo Regimental no Recurso Extraordinário n 793.564-PE. Plenário, Rel. Ministro Marco Aurélio, DJe 01.10 .2014 .

BRENNAN, G.; BUCHANAN, J. The Power to Tax: Analytical Foundations of a Fiscal Constitution. Cambridge: Cambridge University Press, 1980.

BRETON, Albert. Modelling vertical competition. In: AHMAD, Ehtisham; BROSIO, Giorgio. (eds.). Handbook of Fiscal Federalism. Cheltenham: Edward Elgar, 2006.

BURGESS, Michael. Comparative Federalism: Theory and Practice. London: Routledge, 2006.

CABRAL, Nazaré da Costa. A teoria do federalismo financeiro. Coimbra: Almedina, 2015.

CARRAZZA, Roque Antonio. Curso de direito constitucional tributário. São Paulo: Malheiros, 1999.

COÊLHO, Sacha Calmon Navarro. Curso de direito tributário brasileiro. Rio de Janeiro: Forense, 2018.

COÊLHO, Sacha Calmon Navarro. Contribuições no direito brasileiro: seus problemas e soluções. In: DERZI, Misabel de Abreu Machado (org.). Separação de poderes e efetividade do sistema tributário. Belo Horizonte: Del Rey, 2010.

CORWIN, Edward S. The passing of dual federalism. Virginia Law Review, v. 36, n. 01, p. 01-24, 1950.

COSTA, Alcides Jorge. História da tributação no Brasil: da República à Constituição de 1988. In: SANTI, Eurico Marcos Diniz de. Curso de direito tributário e finanças públicas. São Paulo: Saraiva, 2008.

DA SILVA, José Afonso. Curso de direito constitucional positivo. São Paulo: Malheiros, 2011.

DERZI, Misabel Abreu Machado. O princípio da não afetação da receita de impostos e a justiça distributiva. HORVATH, Estevão; CONTI, José Maurício; SCAFF, Fernando Facury (Org.). Direito Financeiro, Econômico e Tributário: estudos em homenagem a Regis Fernandes de Oliveira. São Paulo: Quartier Latin, 2014.

DERZI, Misabel Abreu Machado;DE BUSTAMANTE, Thomas da Rosa. O princípio federativo e a igualdade: uma perspectiva crítica para o sistema jurídico brasileiro a partir da análise do modelo alemão. In: DERZI, Misabel de Abreu Machado; BATISTA JÚNIOR, Onofre Alves; MOREIRA, André Mendes. Estado federal e guerra fiscal no direito comparado. Belo Horizonte: Arraes, 2015.

DERZI, Misabel Abreu Machado. Direito tributário, direito penal e tipo. São Paulo: Editora Revista dos Tribunais, 2007. 
FØLLESDAL, Andreas. Competing Conceptions of Subsidiarity. In: FLEMING, James E.; LEVY, Jacob T. Federalism and Subsidiarity. New York: New York University Press, 2014.

FONROUGE, Giuliani. Derecho financiero. Buenos Aires: La Ley, 2004.

GUASTINI, Riccardo. Interpretar y argumentar. Madrid: Centro de Estudios Políticos y Constitucionales, 2014.

HESSE, Konrad. Elementos de direito constitucional da República Federal da Alemanha. Porto Alegre: Sergio Antonio Fabris Editor, 1998.

HORTA, Raul Machado. Organização Constitucional do Federalismo. Revista da Faculdade de Direito da UFMG, $\mathrm{n}$. 28-29, p. 09-32, 1986

HUEGLIN, Thomas O. Early modern concepts for a late modern world: Althusius on community and federalism. Waterloo: Wilfrid Laurier University Press, 1999.

HUEGLIN, Thomas O. Federalism, Subsidiarity and the European Tradition: Some Clarifications. Telos, n. 100, p. 37-55, 1994.

HUEGLIN, Thomas O. ; FENNA, Alan. Comparative Federalism: A Systematic Inquiry. Toronto: University of Toronto Press, 2015.

LOBATO, Valter. O regime jurídico-constitucional das contribuições destinadas ao custeio da seguridade social: a importância basilar e estruturante da finalidade e os demais limites ao poder de tributar. 2014. Tese (Doutorado em Direito) - Faculdade de Direito, Universidade Federal de Minas Gerais, Belo Horizonte.

LOBATO, Valter. O custeio da seguridade social e os benefícios de risco: os princípios aplicáveis e os limites ao poder de tributar. In: DERZI, Misabel de Abreu Machado (org.). Separação de poderes e efetividade do sistema tributário. Belo Horizonte: Del Rey, 2010.

MAJOCCHI, Alberto. Theories of Fiscal Federalism and the European Experience. In: WARD, Ann; WARD, Lee. (eds.). The Ashgate Research Companion to Federalism. Farnham: Ashgate, 2009.

MOOTS, Glenn A. The Covenant Tradition of Federalism: The Pioneering Studies of Daniel J. Elazar. In: WARD, Ann; WARD, Lee. (eds.). The Ashgate Research Companion to Federalism. Farnham: Ashgate, 2009.

MOREIRA, André Mendes; DERZI, Misabel de Abreu Machado; BATISTA JÚNIOR, Onofre Alves. (orgs.). Estado federal e tributação: das origens à crise atual. Belo Horizonte: Arraes Editores, 2015.

MÜLLER, Friedrich. Métodos de trabalho no direito constitucional. Rio de Janeiro: Renovar, 2005.

MÜLLER, Friedrich. Teoria estruturante do direito. São Paulo: Revista dos Tribunais, 2008.

OLIVEIRA, Fabrício Augusto. Teorias da federação e do federalismo fiscal: o caso brasileiro. Texto para discussão n. 43. Belo Horizonte: Fundação João Pinheiro, 2007.

OLIVEIRA, Fabrício Augusto; CHIEZA, Rosa Angela. Auge e declínio da federação brasileira: 1988-2017. In: ANFIP; FENAFISCO. A Reforma Tributária Necessária: diagnóstico e premissas. Brasília/São Paulo: Plataforma Política Social, 2018.

RILKER, W. Federalism. In: GREENSTEIN, F.; POLSBY N. (eds.). The Handbook of Political Science: Government Institutions and Processes. Boston: Addison-Wesley Pub. Co., 1975.

SACCHETTO, C. Analysis of Fiscal Federalism from a Comparative Tax Law Perspective. In: BIZIOLI, G.; SACCHETTO, C. (eds.). Tax Aspects of Fiscal Federalism: A Comparative Analysis. Amsterdam: IBFD, 2011.

SCHOUERI, Luís Eduardo. A lei complementar e a repartição de competências tributárias. In: COSTA, Alcides Jorge. Sistema Tributário Nacional e a estabilidade da federação brasileira. São Paulo: Noeses, 2012.

SCHOUERI, Luís Eduardo. Direito tributário. São Paulo: Saraiva Educação, 2018.

SCHÜTZE, Robert. From Dual to Cooperative Federalism: The Changing Structure of European Law. Oxford: Oxford University Press, 2009.

SHAH, Anwar. Introduction: Principles of Fiscal Federalism. In: SHAH, Anwar. The Practice of Fiscal Federalism: Comparative Perspectives. Montréal: McGill-Queen's University Press, 2007. 
Thiago Álvares Feital

SOUZA NETO, Cláudio Pereira de; SARMENTO, Daniel. Direito constitucional: teoria, história e métodos de trabaIho. Belo Horizonte: Fórum, 2012. ed. eletr.

SPAGNOL, Werther Botelho. As contribuições sociais no direito brasileiro. Rio de Janeiro: Forense, 2002.

VILE, M.J.C. Federal Theory and the "New Federalism". In: JAENSCH, D. (ed.) The Politics of New Federalism. Adelaide: Australian Political Studies Association, 1977.

Recebido/Received: 28.03.2019.

Aprovado/Approved: 04.07.2020. 